\title{
Should UK membership exams be held overseas? No
} Graeme Muir and Justin Thacker (doi:10.1136/bmj.d4566) believe that UK professional qualifications can help other countries improve training and standards, but Delan Devakumar and Kate Mandeville argue that they lack local relevance

\author{
Delan Devakumar Wellcome Trust research fellow ${ }^{1}$, Kate Mandeville Wellcome Trust research \\ fellow ${ }^{2}$
}

${ }^{1}$ University College London, London, UK; ${ }^{2}$ London School of Hygiene and Tropical Medicine

While membership exams from UK medical colleges and faculties are an integral part of training for UK doctors, we believe that they are rarely appropriate and may be damaging in the long term when taken overseas.

All but one of the colleges run membership exams abroad, predominantly in Asian Commonwealth countries. ${ }^{1}$ From a historical perspective, this practice is understandable because medical training in many of these countries is based on the UK model. In the past, it was common for doctors to come to the UK for further postgraduate training, where many took the membership exams. Membership status thus gained reputational value in originating countries, leading to continued demand for these exams today. So the colleges' decision to transport the exams overseas could be viewed as a natural progression, with financial benefits for the colleges and convenience for local candidates.

However, UK membership exams are no longer the necessity they once were. Many of these countries have developed their own postgraduate training and examinations, ${ }^{2}$ which better reflect local context. In this changed world, we believe that UK colleges should not run their membership exams overseas because they are not locally relevant, undermine local postgraduate training, and may not reflect population needs.

\section{Not locally relevant}

The knowledge and skills required to pass college exams reflect those of a doctor working in the UK, with its specific disease burden and management unavailable in many other countries. Although components of the UK exams are applicable anywhere, a substantial proportion is context specific and cannot automatically be translated into other settings. ${ }^{3}$ For example, although the principles of the UK Mental Health Act could be applicable to other settings, the specifics are relevant only to UK practitioners. In addition, the assessment methods of the exams may be inappropriate for a local setting. ${ }^{4}$ Furthermore, it follows that if UK exams were so readily relevant to other settings, UK trainees would be automatically equipped to work competently in any other country.

By exporting their exams to other countries, the UK colleges confer legitimacy on them, convincing candidates of their relevance. Although it could be argued that they promote a higher standard of practice and more effective educational styles, these aims could equally be accomplished through local training guided by college expertise.

We support doctors who seek further professional development and the inclusion of global health in medical education, but we question the merits of overseas qualifications when there is no intention of working in that country. The time and money spent on UK exams could be better used gaining further expertise in the local context.

\section{Undermines postgraduate training}

Postgraduate training is necessary to retain medical graduates and develop a specialist workforce. The WHO global code of practice on the international recruitment of health workers acknowledges the importance of health workers for sustainable health systems and states that "Member States should take effective measures to educate, retain and sustain a health workforce that is appropriate for the specific conditions of each country." 5

However, running UK membership exams overseas may undermine the capacity and development of domestic postgraduate education. This goes against Lord Crisp's recommendation to "strengthen health systems and institutions." If there is already a local postgraduate exam, it will have to compete with the UK exam for reputational value. Although competition could lead to higher standards, a collaborative approach is surely a better use of resources in low income settings.

If there is no local training or exam, the existence of UK exams removes any incentive to develop them. And while doctors migrate for many reasons, holding UK exams in foreign 
countries could encourage migration to the UK in a time of tightening visa restrictions for foreign graduates. ${ }^{7}$

UK exams can be justified as an interim measure when local postgraduate systems have broken down-for example, in conflict or post-conflict situations. A good example of this is the reintroduction of membership exams by several colleges in Iraq. This is, however, a capacity building measure and should not be a permanent solution.

\section{Population needs}

As the NHS Framework for International Development emphasises, UK interventions need to be aligned with the needs of developing countries. ${ }^{8}$ While individual doctors may express a need to take the UK exams, this does not necessarily reflect the medical need of the local population. Similarly, professional associations are primarily accountable to their members. Even if the colleges are invited by local associations to run their exams overseas, they still have a responsibility to assess whether this would meet the needs of both the population and the health workforce. Any financial benefits should take second place to the overall health needs of a country.

\section{Alternatives}

We agree with partnerships where knowledge and expertise can pass in both directions and recognise the need to support colleagues overseas. Rather than running UK exams overseas, we suggest the colleges could use their considerable expertise in assessment and accreditation to strengthen local training. A good example is where the RCPCH has helped to develop a new diploma in Palestinian child health, aimed at general practitioners working within the occupied Palestinian Territories. ${ }^{9}$ Alternatively the colleges could develop an international version or components of their exams, removing the UK focus and working with country trainers to adapt it to the local setting, as the Royal College of General Practitioners has done with the MRCGP[INT].$^{10}$ Strengthening regional postgraduate exams, such as membership of the West African College of Physicians, would also be a preferable alternative.
If colleges hold exams overseas, there should be a transparent process whereby both donor and recipient organisations provide evidence to an independent body that it will be relevant to the health needs of the local population. UK postgraduate medical exams are a valuable tool in the education of UK doctors but are not directly exportable to other countries. Overall, we feel that providing assistance to the local system is a preferable use of UK expertise.

Competing interests: All authors have completed the ICMJE uniform disclosure form at www.icmje.org/coi_disclosure.pdf (available on request from the corresponding author) and declare: no support from any organisation for the submitted work; no financial relationships with any organisations that might have an interest in the submitted work in the previous three years, no other relationships or activities that could appear to have influenced the submitted work.

Provenance and peer review: Commissioned; not externally peer reviewed.

1 MRCP(UK) Part 1 examination—centres outside the UK. www.mrcpuk.org/Part1/Pages/ Part10SCentres.aspx

2 Royal College of Physicians. RCP in South Asia. www.rcplondon.ac.uk/international/south asia/rcp-south-asia.

3 Lee ACK, Hall JA, Mandeville KL. Global public health training in the UK: preparing for the future. J Public Health 2011;33:310-6.

4 Mirza, DM. Promoting unprofessionalism in the UAE? Educ Prim Care 2010;21:132.

5 WHO. World Health Organization global code of practice on the international recruitment of health personnel. 63rd World Health Assembly. WHA63.16. 2010. www.who.int/hrh/ migration/code/code_en.pdf.

6 Crisp N. Global health partnerships: the UK contribution to health in developing countries. www.dh.gov.uk/en/Publicationsandstatistics/Publications/PublicationsPolicyAndGuidance/ DH_065374.

7 NHS Employers. Working and training in the National Health Service-a guide for international medical graduates thinking about working or training in the UK. 2010. www. nhsemployers.org/Aboutus/Publications/Pages/Working-and-training-in-the-NationalHealth-Service.aspx.

8 Department of Health. Framework for NHS involvement in international development. www.ihlc.org.uk/news/documents/framework.pdf.

9 Waterston T, Halileh S, Odeh J, Rudolf M, Hamilton P. Teaching child health in the occupied Palestinian territory. Lancet 2009;373:878-80.

10 Royal College of General Practitioners. What is MRCGP[INT]? www.rcgp.org.uk/ international/mrcgp_int/what_is_mrcgp_int.aspx.

Cite this as: $B M J$ 2011;343:d4560 